\title{
Estimativas de correlações genotípicas e de ambiente em gerações com elevada freqüência de heterozigotos
}

\author{
Genotypic and enviromental correlation estimates with high heterozygous frequency
}

\begin{abstract}
Giovani Benin ${ }^{1}$ Fernando Irajá Félix de Carvalho ${ }^{1}$ Antonio Costa de Oliveira ${ }^{2}$ Irineu Hartwig ${ }^{1}$ Douglas Schmidt ${ }^{1}$ Eduardo Alano Vieira ${ }^{1}$ Igor Pires Valério ${ }^{3}$ José Gonzáles da Silva ${ }^{1}$
\end{abstract}

\section{RESUMO}

A correlação genotípica permite avaliar a magnitude e a direção da associação entre caracteres, sendo de grande utilidade por permitir a viabilidade do emprego da seleção indireta, que em alguns casos, pode levar a progressos genéticos mais rápidos e altamente expressivos em programas de melhoramento de aveia (Avena sativa L.). O objetivo deste trabalho foi avaliar a viabilidade da implementação de uma modificação na fórmula de PETR \& FREY (1966), para a obtenção de estimativas de correlação genotípica, fenotípica e de ambiente, através da análise de quatro populações segregantes $F_{2}$ de aveia: OR 2 x UPF 18, UPF 7 x CTC 5, OR 2 x UPF 7, UPF 18 x CTC 5. As estimativas de correlação genotípica indicam que a seleção de plantas de alta produtividade de grãos pode ser realizada indiretamente através dos caracteres número de panículas por planta, peso de panícula, número de grãos por panícula e peso médio de grãos. Entretanto, as diferenças em magnitude e direção das estimativas de correlações, entre os vários pares de caracteres, nas quatro populações estudadas, não permitem a generalização de uma estratégia de seleção, isto devido as limitações impostas pelas diferenças entre as constituições genéticas dos genitores $e$ populações. Desta forma, é de fundamental importância a avaliação da capacidade combinatória das principais constituições genéticas utilizadas em cruzamentos artificiais, a fim de se estabelecer critérios mais efetivos a serem empregados na seleção de genótipos superiores.

Palavras-chave: Avena sativa L., melhoramento genético, critério de seleção, fenótipo, genótipo.

\begin{abstract}
The use of genotypic correlation helps evaluating the magnitude and direction of associations between characters facilitating the application of indirect selection, leading to faster and larger genetic gains in oat (Avena sativa L.) breeding programs. This study aimed at testing a modification of PETR \& FREYS' (1996) formula, to obtain genotypic, phenotypic and environmental correlation estimates through the analyses of four $F_{2}$ oat segregant populations: OR $2 \times U P F 18$, UPF $7 \times$ CTC 5, OR $2 \times$ UPF 7 and UPF $18 \times$ CTC 5. The estimates of genetic correlations indicated that plants of superior grain productivity could be selected indirectly through the characters: number of panicles per plant, panicle weight, number of grains per panicle and average grain weight. However, the opposite direction and the difference of magnitude of correlation estimates between many pairs of characters on the four studied populations did not allow any generalization of selection strategies. This is probably due to the imposed limitations caused by the differences on the genetic background of parents and populations. In this way, it is advisable to test the combining ability of major genotypes used in artificial crossings in Brazil, to establish more effective criteria for superior genotype selection.
\end{abstract}

Key words: Avena sativa L., genetic improvement, selection criteria, phenotype, genotype.

\footnotetext{
${ }^{1}$ Engenheiro Agrônomo, Doutor, Pós-doutorando em Agronomia (Setor de Genômica e Fitomelhoramento) na Universidade Federal de Pelotas (UFPel) - Bolsista do Conselho Nacional de Desenvolvimento Científico e Tecnológico, Brasil. E-mail: giovani.bn@gmail.com

${ }^{2}$ Engenheiro Agrônomo, PhD, Professor do Departamento de Fitotecnia da Faculdade de Agronomia Eliseu Maciel (FAEM/UFPel), Campus Universitário CP 354, 96001-970, Pelotas, RS, Brasil.

${ }^{3}$ Estudante do Curso de Agronomia da UFPel, Brasil.
} 


\section{INTRODUÇÃO}

A correlação é uma medida do grau com que duas variáveis variam juntas ou da intensidade de associação entre essas variáveis (STEEL \& TORRIE, 1960). O conhecimento da associação entre caracteres agronômicos e morfológicos pode ser primordial quando da necessidade de ser feita seleção simultânea de caracteres. Além disso, ao selecionar caracteres de alta herdabilidade e de fácil aferição, e que evidenciem alta correlação com o caráter desejado, o melhorista poderá obter progressos mais rápidos em relação ao uso de seleção direta (SANTOS \& VENCOVSKY, 1986; CARVALHO et al., 2004).

Efeitos genéticos e de ambiente podem influir direta ou indiretamente sobre o caráter rendimento de grãos e os demais caracteres agronômicos importantes na seleção de plantas (FEHR, 1987). Entretanto, a seleção de genótipos superiores tem sido uma tarefa de execução complexa, uma vez que os caracteres de importância agronômica, em sua maioria quantitativos, apresentam base genética complexa, além de serem altamente influenciados pelo ambiente. Desta forma, a correlação fenotípica pode ter pouca aplicabilidade, podendo induzir o melhorista a erros (CHAUDAURY et al., 1973). Assim, é importante distinguir as causas genéticas e de ambiente que, combinadas, resultam na correlação fenotípica (ALMEIDA, 1988). Através da avaliação de três populações segregantes de aveia nas gerações $F_{2}$ e $F_{3}$, KUREK et al. (2002) e BENIN et al. (2003a) evidenciaram correlações genotípicas e de ambiente significativas e de elevada magnitude entre caracteres de importância agronômica e qualidade industrial, sugerindo que a seleção indireta, através de caracteres correlacionados, pode ser efetiva já nas primeiras gerações de um cruzamento.

Quando a seleção é realizada em gerações com alta freqüência de heterozigotos, com base na planta individual, além das dificuldades inerentes à ação gênica, o efeito de ambiente na manifestação fenotípica e a reduzida disponibilidade de sementes, são os principais fatores restritivos às avaliações. Estes fatores, somados à heterogeneidade do solo e à dificuldade de selecionar em ambientes distintos, acabam determinando um maior erro experimental. Nestas condições, procedimentos estatísticos que possibilitem a partição da variância fenotípica em componentes genéticos, principalmente em gerações com elevada freqüência de heterozigotos, são altamente desejáveis.

Existem diversos métodos para a obtenção de estimativas de correlação em plantas autógamas, desenvolvidos em função do delineamento experimental, das características próprias de diferentes populações e do ambiente de cultivo (CARVALHO et al., 2004). Dentre estes, aqueles utilizados em gerações segregantes, conforme PETR \& FREY (1966) e KUREK et al. (2002), visam separar o componente genético e de ambiente através da avaliação dos genitores e suas respectivas populações. Neste contexto, é importante investigar que proporções podem ser atribuídas a fatores gênicos, a fim de se verificar a possibilidade de resposta à seleção nas gerações seguintes de melhoramento. Desta forma, é possível saber se os caracteres de uma população são geneticamente dependentes ou independentes, isto é, se tendem ou não a permanecerem associados nas progênies durante os sucessivos ciclos de seleção.

O objetivo deste trabalho foi avaliar a viabilidade da implementação de uma modificação na fórmula de PETR \& FREY (1966), para a obtenção de estimativas de correlação genotípica, fenotípica e de ambiente, através da análise de quatro populações segregantes $\mathrm{F}_{2}$ de aveia: OR 2 x UPF 18, UPF 7 x CTC 5 , OR 2 x UPF 7, UPF 18 x CTC 5.

\section{MATERIAL E MÉTODOS}

O experimento foi instalado no campo experimental do Setor de Fitomelhoramento da Faculdade de Agronomia Eliseu Maciel - UFPel, no município de Capão do Leão, na safra agrícola de 2001. Os caracteres agronômicos utilizados para a obtenção das estimativas de correlações foram avaliados em 50 plantas individuais para cada genitor e em 400 plantas $\mathrm{F}_{2}$, para cada um dos quatro cruzamentos estudados: OR 2 x UPF 18, UPF 7 x CTC 5, OR 2 x UPF 7, UPF 18 x CTC 5. As cultivares UPF 18, UPF 7, OR 2 e CTC 5 foram utilizadas em cruzamentos devido a suas médias elevadas e seus contrastes para caracteres agronômicos e de qualidade do grão (COMISSÃO..., 2000).

As plantas individuais foram semeadas em linhas de 3 metros de comprimento com espaçamento de 0,3 metros entre e dentro de linhas. A adubação foi realizada de acordo com a COMISSÃO... (1994), a partir da análise de solo. A adubação de cobertura foi efetuada 20 dias após a emergência das plântulas, na forma de uréia, na quantidade de $100 / \mathrm{kg} \mathrm{ha}^{-1}$. O controle de plantas daninhas foi realizado manualmente.

A aferição das diversas variáveis foi realizada segundo a seguinte metodologia: a) ciclo vegetativo: quantificado em número de dias entre a emergência das plântulas e a emissão da panícula

Ciência Rural, v.35, n.3, mai-jun, 2005. 
principal; b) estatura de planta: obtida pela distância em $\mathrm{cm}$ entre a base do colmo e o topo da panícula principal, sem a inclusão das aristas. A planta e a panícula principal foram colhidas separadamente e avaliadas em laboratório, onde foram aferidos os seguintes caracteres: c) número de panículas por planta: obtido pela contagem do número afilhos viáveis de cada planta; d) produção de grãos por planta: obtido em gramas pela trilha individual de plantas e posterior pesagem dos grãos; e) peso de panícula: determinado em gramas através da pesagem da panícula principal; f) número de grãos por panícula: obtido através da trilha de cada panícula principal/planta, sendo considerados apenas os grãos primários e secundários; g) peso médio de grãos: obtido através da divisão entre o peso de grãos e o número de grãos/ panícula.

A fórmula para o cálculo da correlação fenotípica $\left(r_{p}\right)$ seguiu o modelo descrito por STEEL \& TORRIE (1960):

$$
r_{P}=\frac{\mathrm{COV}_{2 X Y}}{\sqrt{V_{X} \times V_{Y}}}
$$

onde: $\mathrm{COV}_{\mathrm{F} 2 \mathrm{XY}}$ - covariância entre os caracteres $\mathrm{X}$ e $\mathrm{Y} ; \mathrm{V}_{\mathrm{x}}$ e $\mathrm{V}_{\mathrm{y}}$ - Variância dos caracteres X e Y. A correlação genotípica foi obtida através de uma adaptação ao modelo proposto por PETR \& FREY (1966):

$$
\mathrm{r}_{\mathrm{G}}=\frac{\mathrm{COV}_{\mathrm{F}_{2 X Y}}-\left(\frac{\mathrm{COV}_{\mathrm{P} 1 \mathrm{XY}}+\mathrm{COV}_{\mathrm{P} 2 \mathrm{XY}}}{2}\right)}{\sqrt{\left(\mathrm{V}_{\mathrm{F} 2 \mathrm{X}}-\left(\frac{\mathrm{V}_{\mathrm{P} 1 \mathrm{X}}+\mathrm{V}_{\mathrm{P} 2 \mathrm{X}}}{2}\right)\right) \times\left(\mathrm{V}_{\mathrm{F} 2 \mathrm{Y}}-\left(\frac{\mathrm{V}_{\mathrm{P} 1 \mathrm{Y}}+\mathrm{V}_{\mathrm{P} 2 \mathrm{Y}}}{2}\right)\right)}}
$$

Onde: $\mathrm{COV}_{\mathrm{P} 1 \mathrm{XY}}, \mathrm{COV}_{\mathrm{P} 2 \mathrm{XY}}$ - covariâncias dos genitores $\mathrm{P}_{1}$ e $\mathrm{P}_{2}$ para os caracteres X e Y; $\mathrm{COV}_{\mathrm{F} 2 \mathrm{XY}}$ - covariância da população $\mathrm{F}_{2}$ para os caracteres $\mathrm{X}$ e $\mathrm{Y}$; $\mathrm{V}_{\mathrm{F} 2 \mathrm{X}}$ e $\mathrm{V}_{\mathrm{F} 2 \mathrm{Y}}-$ Variância da população $\mathrm{F}_{2}$ para os caracteres $\mathrm{X}$ e $\mathrm{Y}$; $V_{\mathrm{P} 1 \mathrm{X}}, \mathrm{V}_{\mathrm{P} 1 \mathrm{Y}}$ e $\mathrm{V}_{\mathrm{P} 2 \mathrm{X}}, \mathrm{V}_{\mathrm{P} 2 \mathrm{Y}}$ - Variância dos genitores $\mathrm{P}_{1}$ e $\mathrm{P}_{2}$ para os caracteres X e Y. A correlação de ambiente $\left(r_{E}\right)$ foi obtida pela diferença entre a correlação fenotípica e genotípica: $r_{E}=r_{P}-r_{G}$, onde: $\mathrm{r}_{\mathrm{E}}$ - correlação de ambiente; $r_{P}$ - correlação fenotípica; $r_{G}$ - correlação genotípica. A estatística do teste t foi utilizada para a verificação formal de hipóteses, para determinar se existe correlação linear significativa entre duas variáveis. Este método utiliza a distribuição t de Student (CARVALHO et al., 2004), com n - 2 graus de liberdade, através do seguinte modelo:

$$
t=\frac{r}{\sqrt{1-r^{2}}} \sqrt{n-2}
$$

onde: $r$ - é o coeficiente de correlação entre os caracteres $\mathrm{X}$ e $\mathrm{Y} ; \mathrm{r}^{2}=$ grau de ajuste da reta de regressão aos dados, ou simplesmente $(r)^{2}$; n - são os graus de liberdade correspondentes a cada geração $\left(\mathrm{P}_{1}, \mathrm{P}_{2}\right.$ e $\left.\mathrm{F}_{2}\right)$.

\section{RESULTADOS E DISCUSSÃO}

As diferenças em magnitude e direção das estimativas de correlações fenotípicas, genotípicas e de ambiente entre os vários pares de caracteres avaliados nas quatro populações demonstram a presença de distintas tendências de associação, quando são consideradas diferentes populações, tais como as correlações observadas entre os caracteres número de panículas por planta x peso de panícula, número de panículas por planta x número de grãos por panícula, número de panículas por planta x peso médio de grãos, número de panículas por planta x ciclo vegetativo, número de panícula por planta x estatura de planta, peso de panícula x peso médio de grãos, peso de panícula $\mathrm{x}$ ciclo vegetativo, número de grãos por panícula x peso médio de grãos, número de grãos por panícula $\mathrm{x}$ ciclo vegetativo, peso médio de grãos $\mathrm{x}$ ciclo vegetativo e ciclo vegetativo $\mathrm{x}$ estatura de planta (Tabela 1). Isto demonstra que o conceito de correlação é semelhante àquele de herdabilidade, devendo ser restrito à constituição genética avaliada e ao ambiente sob estudo. Esta discordância pode ser atribuída a efeitos modificadores do ambiente e a diferentes mecanismos fisiológicos controlando a expressão de caracteres (FALCONER, 1987; CARVALHO et al., 2004), assim como as diferenças na capacidade de combinação apresentadas pelos genitores (LORENCETTI et al., 2004). A presença de significância até mesmo para valores baixos de correlação evidenciados neste trabalho está, segundo VASCONCELLOS et al. (1998) e KUREK et al. (2002) associada aos elevados graus de liberdade incluídos no teste $t$.

Foi observada considerável influência do ambiente (correlação de ambiente) na manifestação de grande parte dos caracteres avaliados, estando de acordo com KUREK et al. (2002) e BENIN et al. (2003a). Valores positivos de correlação de ambiente, tal como as observadas entre os caracteres peso de panícula $\mathrm{x}$ número de grãos por panícula $(0,815)$, produção de grãos por planta x número de grãos por panícula $(0,320)$ e produção de grãos por planta x número de panículas por planta $(0,251)$ para o cruzamento UPF 18 x CTC 5 , indicam que ambos os caracteres foram prejudicados ou beneficiados pelas mesmas variações de ambiente e valores negativos, tal como os observados entre os caracteres produção de grãos por planta x peso de panícula $(-0,128)$ e número de grãos por panícula $\mathrm{x}$ peso médio de grãos $(-0,259)$ para o cruzamento OR 2 x UPF 7, apontam que o ambiente favoreceu um caráter 
Tabela 1 - Estimativa dos coeficientes de correlações fenotípicas $\left(\mathrm{r}_{\mathrm{P}}\right)$, genotípica $\left(\mathrm{r}_{\mathrm{G}}\right)$ e de ambiente $\left(\mathrm{r}_{\mathrm{E}}\right)$ entre sete caracteres avaliados em quatro cruzamentos de aveia (Avena sativa L.). FAEM/UFPel - Pelotas/RS, 2004.

\begin{tabular}{|c|c|c|c|c|c|}
\hline \multirow{2}{*}{ Caracteres } & \multicolumn{5}{|c|}{ Populações segregantes } \\
\hline & Correlações & UPF 18 x CTC 5 & OR 2x UPF 7 & UPF 7 x CTC 5 & OR 2 X UPF 18 \\
\hline Produção de grãos por planta & $\mathrm{r}_{\mathrm{G}}$ & $0,481^{*}$ & $0,763^{*}$ & $0,479^{*}$ & $-0,032^{\mathrm{ns}}$ \\
\hline $\mathrm{X}$ & $\mathrm{r}_{\mathrm{p}}$ & $0,732 *$ & $0,792 *$ & $0,763 *$ & $0,093^{\text {ns }}$ \\
\hline Número de panículas por planta & $\mathrm{r}_{\mathrm{E}}$ & $0,251^{*}$ & $0,029^{\text {ns }}$ & $0,284^{*}$ & $0,125^{*}$ \\
\hline Produção de grãos por planta & $\mathrm{r}_{\mathrm{G}}$ & $0,437^{*}$ & $0,638^{*}$ & $0,548^{*}$ & $0,391^{\mathrm{ns}}$ \\
\hline $\mathrm{X}$ & $\mathrm{r}_{\mathrm{P}}$ & $0,601 *$ & $0,510^{*}$ & $0,635^{*}$ & $0,489 *$ \\
\hline$\underline{\text { Peso de panícula }}$ & $\mathrm{r}_{\mathrm{E}}$ & $0,164 *$ & $-0,128 *$ & $0,087^{\mathrm{ns}}$ & $0,323 *$ \\
\hline Produção de grãos por planta & $r_{G}$ & $0,124^{*}$ & $0,389^{*}$ & $0,505^{*}$ & $0,103^{\text {ns }}$ \\
\hline $\mathrm{X}$ & $\mathrm{r}_{\mathrm{p}}$ & $0,446^{*}$ & $0,456^{*}$ & $0,563^{*}$ & $0,361^{*}$ \\
\hline Número de grãos por panícula & $\mathrm{r}_{\mathrm{E}}$ & $0,320 *$ & $0,067^{\mathrm{ns}}$ & $0,058^{\text {ns }}$ & $0,258 *$ \\
\hline Produção de grãos por planta & $\mathrm{r}_{\mathrm{G}}$ & $0,506^{*}$ & $0,148^{*}$ & $0,176^{*}$ & $0,176^{*}$ \\
\hline $\mathrm{X}$ & $r_{P}$ & $0,295^{*}$ & $0,165^{*}$ & $0,221 *$ & $0,185^{*}$ \\
\hline Peso médio de grãos & $\mathrm{r}_{\mathrm{E}}$ & $-0,211^{*}$ & $0,017^{\mathrm{ns}}$ & $0,045^{\text {ns }}$ & $0,009^{\text {ns }}$ \\
\hline Produção de grãos por planta & $\mathrm{r}_{\mathrm{G}}$ & $-0,126^{*}$ & $-0,162 *$ & $0,024^{\mathrm{ns}}$ & $-0,159 *$ \\
\hline $\mathrm{X}$ & $r_{p}$ & $-0,080^{*}$ & $-0,110^{\mathrm{ns}}$ & $-0,026^{\mathrm{ns}}$ & $-0,062^{\text {ns }}$ \\
\hline Ciclo vegetativo & $\mathrm{r}_{\mathrm{E}}$ & $0,046^{\text {ns }}$ & $0,052^{\mathrm{ns}}$ & $-0,050^{\text {ns }}$ & $0,097^{\mathrm{ns}}$ \\
\hline Produção de grãos por planta & $\mathrm{r}_{\mathrm{G}}$ & $0,180^{*}$ & $0,456^{*}$ & $0,385^{*}$ & $0,131^{*}$ \\
\hline $\mathrm{X}$ & $\mathrm{r}_{\mathrm{P}}$ & $0,256^{*}$ & $0,481 *$ & $0,387 *$ & $0,239 *$ \\
\hline Estatura de planta & $\mathrm{r}_{\mathrm{E}}$ & $0,076^{\text {ns }}$ & $0,025^{\text {ns }}$ & $0,002^{\text {ns }}$ & $0,108^{\text {ns }}$ \\
\hline Número de panículas por planta & $\mathrm{r}_{\mathrm{G}}$ & $0,647^{*}$ & $-0,030^{\mathrm{ns}}$ & $0,270^{*}$ & $-0,130 *$ \\
\hline $\mathrm{X}$ & $r_{p}$ & $0,381 *$ & $0,240^{*}$ & $0,319 *$ & $-0,028^{\mathrm{ns}}$ \\
\hline Peso de panícula & $\mathrm{r}_{\mathrm{E}}$ & $-0,266 *$ & $0,270^{*}$ & $0,049^{\mathrm{ns}}$ & $0,158^{*}$ \\
\hline Número de panículas por planta & $\mathrm{r}_{\mathrm{G}}$ & $0,318^{*}$ & $0,094^{\mathrm{ns}}$ & $0,207^{*}$ & $-0,175^{*}$ \\
\hline $\mathrm{X}$ & $r_{p}$ & $0,272 *$ & $0,250^{*}$ & $0,341 *$ & $-0,050^{\mathrm{ns}}$ \\
\hline Número de grãos por panícula & $\mathrm{r}_{\mathrm{E}}$ & $-0,046^{\mathrm{ns}}$ & $0,156^{*}$ & $0,134 *$ & $0,125^{*}$ \\
\hline Número de panículas por planta & $\mathrm{r}_{\mathrm{G}}$ & $0,300^{*}$ & $-0,012^{\text {ns }}$ & $0,098^{\text {ns }}$ & $-0,102^{\text {ns }}$ \\
\hline $\mathrm{X}$ & $r_{p}$ & $0,160^{*}$ & $0,041^{\mathrm{ns}}$ & $0,043^{\text {ns }}$ & $0,014^{\mathrm{ns}}$ \\
\hline Peso médio de grãos & $\mathrm{r}_{\mathrm{E}}$ & $-0,140^{*}$ & $0,053^{\text {ns }}$ & $-0,055^{\mathrm{ns}}$ & $0,116^{*}$ \\
\hline Número de panículas por planta & $\mathrm{r}_{\mathrm{G}}$ & $-0,454^{*}$ & $-0,024^{\mathrm{ns}}$ & $0,149^{*}$ & $-0,012^{\text {ns }}$ \\
\hline $\mathrm{X}$ & $r_{p}$ & $-0,055^{\mathrm{ns}}$ & $0,000^{\mathrm{ns}}$ & $-0,008^{\text {ns }}$ & $-0,025^{\mathrm{ns}}$ \\
\hline Ciclo Vegetativo & $\mathrm{r}_{\mathrm{E}}$ & $0,399 *$ & $0,024^{\mathrm{ns}}$ & $-0,157^{*}$ & $-0,013^{\text {ns }}$ \\
\hline Número de panículas por planta & $\mathrm{r}_{\mathrm{G}}$ & $-0,230 *$ & $0,112^{\mathrm{ns}}$ & $0,198^{*}$ & $0,070^{\text {ns }}$ \\
\hline $\mathrm{X}$ & $\mathrm{r}_{\mathrm{P}}$ & $0,104 *$ & $0,210^{*}$ & $0,178^{*}$ & $0,079^{\mathrm{ns}}$ \\
\hline Estatura de planta & $\mathrm{r}_{\mathrm{E}}$ & $0,334 *$ & $0,098^{\text {ns }}$ & $-0,020^{\mathrm{ns}}$ & $0,009^{\text {ns }}$ \\
\hline Peso de panícula & $\mathrm{r}_{\mathrm{G}}$ & $-0,004^{\mathrm{ns}}$ & $0,061^{\mathrm{ns}}$ & $0,583^{*}$ & $0,833^{*}$ \\
\hline $\mathrm{X}$ & $\mathrm{r}_{\mathrm{p}}$ & $0,811^{*}$ & $0,076^{\text {ns }}$ & $0,858 *$ & $0,832 *$ \\
\hline Número de grãos por panícula & $\mathrm{r}_{\mathrm{E}}$ & $0,815^{*}$ & $0,015^{\text {ns }}$ & $0,275^{*}$ & $-0,001^{\mathrm{ns}}$ \\
\hline Peso de panícula & $r_{P}$ & $0,527^{*}$ & $-0,036^{\mathrm{nS}}$ & $0,289^{*}$ & $0,007^{\mathrm{ns}}$ \\
\hline $\mathrm{X}$ & $\mathrm{r}_{\mathrm{G}}$ & $0,185^{*}$ & $0,261^{*}$ & $0,274 *$ & $0,243^{*}$ \\
\hline Peso médio de grãos & $\mathrm{r}_{\mathrm{E}}$ & $-0,342 *$ & $0,297^{*}$ & $0,015^{\text {ns }}$ & $0,236^{*}$ \\
\hline Peso de panícula & $\mathrm{r}_{\mathrm{G}}$ & $-0,198^{*}$ & $0,091^{\text {ns }}$ & $0,150^{*}$ & $0,387 *$ \\
\hline $\mathrm{X}$ & $\mathrm{r}_{\mathrm{P}}$ & $0,035^{\text {ns }}$ & $0,058^{\text {ns }}$ & $0,120^{*}$ & $0,303 *$ \\
\hline Ciclo vegetativo & $\mathrm{r}_{\mathrm{E}}$ & $0,233 *$ & $-0,033^{\text {ns }}$ & $-0,030^{\text {ns }}$ & $-0,084^{\mathrm{ns}}$ \\
\hline Peso de panícula & $\mathrm{r}_{\mathrm{G}}$ & $-0,090^{\mathrm{ns}}$ & $0,401^{*}$ & $0,386^{*}$ & $0,311^{*}$ \\
\hline $\mathrm{X}$ & $\mathrm{r}_{\mathrm{P}}$ & $0,306^{*}$ & $0,496 *$ & $0,431 *$ & $0,254^{*}$ \\
\hline Estatura de planta & $\mathrm{r}_{\mathrm{E}}$ & $0,396 *$ & $0,095^{\text {ns }}$ & $0,045^{\text {ns }}$ & $-0,057^{\mathrm{ns}}$ \\
\hline Número de grãos por panícula & $\mathrm{r}_{\mathrm{G}}$ & $-0,261^{*}$ & $-0,584^{*}$ & $-0,254^{*}$ & $-0,376^{*}$ \\
\hline $\mathrm{X}$ & $r_{p}$ & $-0,295^{*}$ & $-0,324 *$ & $-0,186 *$ & $-0,238 *$ \\
\hline Peso médio de grãos & $\mathrm{r}_{\mathrm{E}}$ & $-0,034^{\mathrm{ns}}$ & $-0,259 *$ & $0,068^{\text {ns }}$ & $0,138 *$ \\
\hline Número de grãos por panícula & $\mathrm{r}_{\mathrm{G}}$ & $-0,555^{*}$ & $0,107^{\text {ns }}$ & $0,170^{*}$ & $0,422^{*}$ \\
\hline $\mathrm{X}$ & $\mathrm{r}_{\mathrm{P}}$ & $0,047^{\text {ns }}$ & $0,080^{\text {ns }}$ & $0,147^{*}$ & $0,306^{*}$ \\
\hline Ciclo vegetativo & $\mathrm{r}_{\mathrm{E}}$ & $0,602 *$ & $-0,027^{\mathrm{ns}}$ & $-0,023^{\text {ns }}$ & $-0,116^{*}$ \\
\hline Número de grãos por panícula & $\mathrm{r}_{\mathrm{G}}$ & $0,106^{\mathrm{ns}}$ & $0,416^{*}$ & $0,215^{*}$ & $0,098^{\text {ns }}$ \\
\hline $\mathrm{X}$ & $\mathrm{r}_{\mathrm{P}}$ & $0,241 *$ & $0,399 *$ & $0,378^{*}$ & $0,183 *$ \\
\hline Estatura de planta & $\mathrm{r}_{\mathrm{E}}$ & $0,135^{*}$ & $-0,017^{\mathrm{ns}}$ & $0,163 *$ & $0,085^{\mathrm{ns}}$ \\
\hline Peso médio de grãos & $\mathrm{r}_{\mathrm{G}}$ & $0,373^{*}$ & $0,028^{\text {ns }}$ & $-0,088^{\text {ns }}$ & $-0,610^{*}$ \\
\hline X & $\mathrm{r}_{\mathrm{P}}$ & $-0,057^{\mathrm{ns}}$ & $-0,159 *$ & $-0,099^{\text {ns }}$ & $-0,105^{\mathrm{ns}}$ \\
\hline Ciclo vegetativo & $\mathrm{r}_{\mathrm{E}}$ & $-0,430^{*}$ & $-0,187^{*}$ & $-0,011^{\mathrm{ns}}$ & $0,505^{*}$ \\
\hline Peso médio de grãos & $r_{G}$ & $-0,103^{\text {ns }}$ & $-0,128^{*}$ & $0,191 *$ & $0,112^{\mathrm{ns}}$ \\
\hline X & $\mathrm{r}_{\mathrm{P}}$ & $0,059^{\text {ns }}$ & $0,159 *$ & $0,146^{*}$ & $0,150^{*}$ \\
\hline Estatura de planta & $\mathrm{r}_{\mathrm{E}}$ & $0,162 *$ & $0,287 *$ & $-0,045^{\mathrm{ns}}$ & $0,038^{\text {ns }}$ \\
\hline Ciclo vegetativo & $r_{G}$ & $0,064^{\mathrm{ns}}$ & $-0,112^{\mathrm{ns}}$ & $-0,080^{\mathrm{ns}}$ & $0,014^{\mathrm{ns}}$ \\
\hline $\mathrm{X}$ & $\mathrm{r}_{\mathrm{P}}$ & $0,258^{*}$ & $-0,159 *$ & $-0,081^{\mathrm{ns}}$ & $0,135 *$ \\
\hline Estatura de planta & $r_{E}$ & $0,194^{*}$ & $-0,047^{\mathrm{ns}}$ & $0,001^{\mathrm{ns}}$ & $0,151^{*}$ \\
\hline
\end{tabular}

*Significativo a $1 \%$ de probabilidade, pelo teste t, a n-2 GL $(0,115)$.

${ }^{\text {ns }}$ Não significativo.

Ciência Rural, v.35, n.3, mai-jun, 2005. 
em detrimento do outro (FALCONER, 1987). Portanto, fica evidente como as causas de ambiente e genética se combinaram para formar a correlação fenotípica.

No cruzamento UPF 18 x CTC 5 as correlações genotípicas entre os caracteres produção de grãos por planta x peso médio de grãos, número de panículas por planta x peso de panícula, peso de panícula x peso médio de grãos, número de panículas por planta x peso médio de grãos apresentaram magnitudes superiores às suas correspondentes correlações fenotípicas; isto é um indicativo que a expressão fenotípica destes caracteres é reduzida diante das influências do ambiente, devido, provavelmente, as causas de variação genética e de ambiente terem influenciado os caracteres por meio de diferentes mecanismos fisiológicos (FALCONER \& MACKAY, 1997). Resultado semelhante foi encontrado na associação entre os caracteres produção de grãos por planta x peso de panícula no cruzamento OR $2 \mathrm{x}$ UPF 7; também entre os caracteres número de grãos por panícula x ciclo vegetativo no cruzamento OR 2 x UPF 18. Assim, as correlações fenotípicas podem ser úteis na ausência das estimativas de correlação genética (PELUZIO et al., 1998). O mesmo resultado de comportamento foi encontrado em aveia por CHANDHANAMUTTA \& FREY (1973) e em trigo por CAVASSIM \& BORÉM(1998).

Além disto, estimativas de correlação genotípica e fenotípica de similar magnitude, como as observadas entre os caracteres produção de grãos por planta x número de panículas por planta, produção de grãos por planta $\mathrm{x}$ peso de panícula, produção de grãos por planta $\mathrm{x}$ estatura de planta, peso de panícula $\mathrm{x}$ estatura de planta e número de grãos por panícula $\mathrm{x}$ estatura de planta no cruzamento OR 2 x UPF 7, entre os caracteres produção de grãos por planta x peso de panícula, produção de grãos por planta x número de grãos por panícula, produção de grãos por planta $\mathrm{x}$ estatura de planta e peso de panícula $x$ estatura de planta no cruzamento UPF 7 x CTC 5 e entre os caracteres peso de panícula $\mathrm{x}$ número de grãos por panícula e peso de panícula $\mathrm{x}$ ciclo vegetativo no cruzamento OR 2 x UPF 18, possibilitam inferir que a seleção indireta para um destes caracteres resulta em maiores alterações no outro caráter. Ainda na tabela 1 pode ser observado que a correlação genotípica entre produção de grãos por planta x número de grãos por panícula nos cruzamentos UPF 7 x CTC $5(0,505)$ e OR 2 x UPF $7(0,389)$ possibilitam subsídios à seleção de plantas mais produtivas através do caráter número de grãos por panícula, o que não ocorreu para o cruzamento OR 2 x UPF 18, visto que a associação fenotípica foi influenciada por efeitos não genéticos. Para os cruzamentos UPF 18 x CTC $5(0,481)$, OR 2 x
UPF $7(0,763)$ e UPF 7 x CTC $5(0,479)$ as correlações genotípicas positivas e significativas indicam que $o$ número de panículas por planta pode ser uma estratégia a ser considerada na seleção de plantas mais produtivas, conforme já observado por PETR \& FREY (1966) e BENIN et al. (2003a).

Para o cruzamento OR 2 x UPF 18, a correlação genotípica $(-0,032)$ e fenotípica $(0,093)$ entre produção de grãos por planta x número de panícula por planta não foram significativas; a confirmação deste resultado pode ser fornecida pela correlação genotípica entre número de panículas por planta $\mathrm{x}$ número de grãos por panícula $(-0,175)$ demonstrando que o aumento do número de panículas por planta ocasionou redução do número de grãos por panícula, fato este que pode ter por base o balanço entre os componentes de rendimento (GRAFIUS, 1978). A produtividade de grãos em aveia, conforme GRAFIUS (1964) é determinada pela multiplicação dos componentes de rendimento, ou seja, do número de plantas/unidade de área, número de grãos e peso de grãos. Neste sentido, a associação genotípica $(0,437$, $0,638$ e 0,548$)$ e fenotípica $(0,601,0,510$ e 0,635$)$ entre produção de grãos por planta x peso de panícula nos cruzamentos UPF 18 x CTC 5, OR 2 x UPF 7 e UPF 7 x CTC 5, respectivamente, se justificam perfeitamente, visto que o peso da panícula inclui a combinação de dois dos três componentes do rendimento e, principalmente, levando em consideração que os grãos representam $80 \%$ do peso da panícula (CHANDHANAMUTA \& FREY, 1973). Correlações fenotípicas entre o peso de panícula e o rendimento de grãos variaram entre 0,06 e 0,84 em três populações de aveia estudadas (CHAPKO \& BRINKMAN, 1991). Também, apesar da elevada correlação fenotípica entre produção de grãos por planta x peso de panícula $(0,68)$ (CHANDHANAMUTA \& FREY, 1973), estes autores obtiveram correlação genotípica não significativa $(0,33)$, discordando dos resultados observados neste trabalho para os cruzamentos UPF 18 x CTC 5, OR 2 x UPF 7 e UPF 7 x CTC 5. Por outro lado, estes resultados concordam com o resultado encontrado para o cruzamento OR 2 x UPF 18, onde a correlação genotípica $(0,39)$ foi não significativa. Principalmente no cruzamento OR 2 x UPF 7, a superioridade da correlação genotípica $(0,638)$ em relação a fenotípica $(0,510)$ fornece subsídios para a seleção de plantas mais produtivas através do caráter peso de panícula. Confirmando estes resultados, BENIN et al. (2003a) encontrou que o peso de panícula apresentou os maiores efeitos diretos e indiretos sobre o rendimento de grãos, estabelecendo verdadeira relação de causa e efeito entre ambos os caracteres. 
Além de genótipos de ampla adaptabilidade e estabilidade e elevado potencial produtivo, o sucesso da aceitação de uma nova cultivar de aveia está na dependência de sua qualidade do grão. Neste sentido, o tamanho e o peso dos grãos são aspectos de fundamental importância(BOTHANA, 1997; CABRAL et al., 2002). As correlações genotípicas significativas (0,261, -0,584, -0,254 e -0,376) apresentadas na tabela 1 evidenciam que o aumento do número de grãos por panícula tende a reduzir o peso médio do grão, estando de acordo com os, resultados encontrados por CHAPKO\& BRINKMAN(1991), CAIERÃO etal.(2001), KUREK et al. (2002) e CARVALHO et al. (2004). Considerando que CHANDHANAMUTTA \& FREY (1973) atribuíram 80\% do incremento do peso da panícula ao número de grãos por panícula e os restantes $20 \%$ ao peso de grãos, os melhoristas de aveia poderão encontrar dificuldade em selecionar, através do peso da panícula, genótipos com alto potencial de rendimento de grãos e elevado peso de grão.

Para os cruzamentos UPF 18 x CTC $5(0,527)$ e UPF 7 x CTC $5(0,289)$, as estimativas de correlação genotípica apontam que a seleção através do peso de panícula possibilita elevar o peso de grãos, o que não foi observado para os cruzamentos OR 2 x UPF 7 (0,036) e OR 2 x UPF $18(0,007)$. O melhor entendimento do relacionamento entre estes caracteres pode ser fornecido pela análise das estimativas de $\mathrm{r}_{\mathrm{G}}, \mathrm{r}_{\mathrm{P}}$ e $\mathrm{r}_{\mathrm{E}}$. No cruzamento UPF 18 x CTC 5, a elevada correlação fenotípica entre peso de panícula $\mathrm{x}$ número de grãos por panícula $(0,811)$ foi totalmente ocasionada pelo ambiente $(0,815)$, o que resultou em correlação genotípica desprezível $(-0,004)$. Contudo, para o cruzamento OR 2 x UPF 18, o efeito do ambiente é que foi mínimo (-0,001), possibilitando uma estimativa de correlação genotípica $(0,833)$ bem próxima a fenotípica $(0,832)$; pode ser observado que estas correlações afetaram de forma direta a correlação genotípica entre peso de panícula x peso médio de grãos; por exemplo, no cruzamento UPF 18 x CTC 5, a pequena correlação genotípica negativa entre peso de panícula $\mathrm{x}$ número de grãos por panícula $(-0,004)$ e a expressiva correlação genotípica entre peso de panícula x peso médio de grãos $(0,527)$ determinaram que o peso médio do grão foi o principal responsável em elevar o peso da panícula. Entretanto, situação completamente inversa pode ser observada no cruzamento OR 2 x UPF 18, onde, a elevada correlação genotípica entre peso de panícula x número de grãos por panícula $(0,833)$ e a ausência de correlação entre peso de panícula x peso médio de grãos $(0,007)$ indicam que o número de grãos por panícula foi o único caráter linearmente associado ao peso da panícula.
Pelo exposto, a seleção de plantas de maior produtividade de grãos pode ser realizada indiretamente através dos caracteres número de panículas por planta, peso de panícula, número de grãos por panícula e peso médio de grãos. Entretanto, os dados antagônicos observados entre populações não permitem a generalização de uma estratégia de seleção a ser considerada em outras populações segregantes. Fato este que tem por base a intensa diferenciação entre as populações testadas, determinadas provavelmente pelo grande dissimilaridade entre as constituições genéticas utilizadas nas hibridações (BENIN et al., 2003b). Desta forma, é de fundamental importância à avaliação das principais constituições genéticas utilizadas em cruzamentos artificiais em nível de Brasil, para que a seleção indireta de caracteres seja efetuada com maior êxito e precisão.

\section{CONCLUSÕES}

Estimativas de correlação genotípica e de ambiente, em gerações com elevada freqüência de heterozigotos, são parâmetros eficientes para a identificação da melhor estratégia de seleção indireta para o incremento do rendimento de grãos. A eficiência da seleção é altamente dependente da combinação das constituições genéticas utilizadas em hibridações, sendo necessário avaliar o comportamento dos principais genitores utilizados nos cruzamentos.

\section{REFERÊNCIAS BIBLIOGRÁFICAS}

ALMEIDA, A.H.B. Heterose e correlações em plantas branquícas e normais de jerimum caboclo (Cucurbita maxima Duchesne). 1988. 95f. Dissertação (Mestrado em Genética e Melhoramento) - Universidade Federal de Viçosa.

BENIN, G. et al. Estimativas de correlações e coeficientes de trilha como critérios de seleção para rendimento de grãos em aveia. Revista Brasileira de Agrociência, Pelotas, v.9. n.1, p.9-16 2003a.

BENIN, G. et al. Comparações entre medidas de dissimilaridade e estatísticas multivariadas como critérios no direcionamento de hibridações em aveia. Ciência Rural, Santa Maria, v.33, n.4, p.657-662, 2003b.

BOTHANA, C.R.A. Qualidade do grão de aveia: características físicas e regiões genômicas associadas. 1997. 98f. Dissertação (Mestrado em Fitotecnia) - Faculdade de Agronomia, Universidade Federal do Rio Grande do Sul.

CABRAL, C.B. et al. Herança do peso de grãos primários e secundários de aveia. Pesquisa Agropecuária Brasileira, Brasília, v.37, n.1, p.73-80, 2002.

CAIERÃO, E. et al. Seleção indireta em aveia para o incremento no rendimento de grãos. Ciência Rural, Santa Maria, v.31, n.2, p.231-236, 2001.

Ciência Rural, v.35, n.3, mai-jun, 2005. 
CARVALHO, F.I.F. et al. Estimativas e implicações da correlação no melhoramento vegetal. Pelotas : UFPel, 2004. 142p.

CAVASSIM, J.E.; BORÉM, A. Correlações em seis populações de trigo (Triticum aestivum L.). Revista Ceres, Viçosa, v.45, n.262, p.555-566, 1998.

CHANDHANAMUTTA, P.; FREY, K.J. Indirect mass selection for grain yield in oat populations. Crop Science, Madison, v.13, p.470-473, 1973.

CHAPKO, L.B.; BRINKMAN, M.A. Interrelationships between panicle weight, grain yield and grain yield components in oat. Crop Science, Madison, v.31, p.878-882, 1991.

CHAUDAURY, D. et al. Genetic variability and correlation for yield components in rice. Indian Journal of Agricultural Sciences, New Delhi, v.43, n.2, p.181-184, 1973.

COMISSÃO BRASILEIRA DE PESQUISA DE AVEIA. Recomendações técnicas para a cultura da aveia. Pelotas, 2000. 69p.

COMISSÃO DE FERTILIDADE DO SOLO DO RS E SC. Recomendações de adubação e de calagem para os estados do Rio Grande do Sul e de Santa Catarina. 3.ed. Passo Fundo, 1994. 221p.

FALCONER, D.S. Introdução à genética quantitativa. Viçosa:UFV, 1987. 279p.

FALCONER, D.S.; MACKAY, T.F. Introduction to quantitative genetics. 4.ed. Londres : Longman Group, 1997. 464p.

FEHR, W.R. Principles of cultivars development. New York : Macmillan, 1987. 536p.
GRAFIUS, J.E. A geometry for plant breeding. Crop Science, Madison, v.4, p.241-246, 1964.

GRAFIUS, J.E. Multiple characters and correlated response. Crop Science, Madison, v.18, p.931-934, 1978.

LORENCETTI, C. Capacidade combinatória de genitores e suas implicações no desenvolvimento de progênies superiores em aveia (Avena sativa L.). 2004 102f. Doutorado (Doutorado em Agronomia) - Faculdade de Agronomia Eliseu Maciel, Universidade Federal de Pelotas.

KUREK, A.J. et al. Coeficiente de correlação entre caracteres agronômicos e de qualidade de grãos e sua utilidade na seleção de plantas de aveia. Ciência Rural, Santa Maria, v.32, n.3, p.371-376, 2002.

PELUZIO, J.M. et al. Correlações fenotípicas, genéticas e de ambiente entre alguns caracteres de soja, em Pedro Afonso, Tocantins. Revista Ceres, Viçosa, v.45, n.259, p.303-308, 1998.

PETR, F.C.; FREY, K.J. Genotypic correlations, dominance and heritability of quantitative characters in oats. Crop Science, Madison, v.6, p.259-262, 1966.

SANTOS, J.; VENCOVSKY, R. Correlação fenotípica e genética entre alguns caracteres agronômicos do feijoeiro (Phaseolus vulgaris, L.). Ciência e Prática, Lavras, v.10, n.3, p.265-272, 1986.

STEEL, R.G.D.; TORRIE, J.L. Principles and procedures of statistics. New York : McGraw Hill. 1960. 481p.

VASCONCELLOS, N.J.S. et al. Efeito do ambiente e correlação entre componentes do grão em genótipos de aveia cultivados no Sul do Brasil. Revista Brasileira de Agrociência, Pelotas, v.2, n.2, p.85-88, 1998. 